\section{A) Check for updates}

Cite this: Polym. Chem., 2019, 10 5626

Received 25th June 2019, Accepted 26th September 2019

DOI: 10.1039/c9py00929a

rsc.li/polymers

\title{
Synthesis and supramolecular assembly of fluorinated biogenic amine recognition host polymers $\uparrow$
}

\author{
Ervin Kovács, (D) a János Deme, ${ }^{a}$ Gábor Turczel, ${ }^{a}$ Tibor Nagy, (D) a Vajk Farkas, (D) ${ }^{a}$ \\ László Trif, (D) ${ }^{a}$ Sándor Kéki, (D) ${ }^{b}$ Péter Huszthy (D) ${ }^{c}$ and Robert Tuba (D) *a
}

\begin{abstract}
Copolymers containing hydroxyl (i.e. vinyl alcohol, VA) or fluorine functionalities are synthetic macromolecules having prominent biomedical applications. The concentration of hydroxyl groups along the polymer chain controls the polymer polarity. Moreover, the introduction of perfluorinated organic moieties via the $\mathrm{OH}$ functionalities may lead to macromolecules having potential magnetic resonance imaging (MRI) active properties. The ring-opening metathesis polymerization (ROMP) reaction using welldefined ruthenium-catalyzed systems is one of the most promising synthetic tools to fabricate such polymers. Co-polymerization of norbornene grafted pyridino-18-crown-6 ether (7) with fluorine-functionalized norbornenes (10 and $\mathbf{1 1}$ ) results in polymers bearing host molecular moieties. It has been demonstrated that the complexation of these host copolymers with biogenic amines including dopamine hydrochloride (12) and L-alanyl-L-lysine dipeptide hydrochloride (13) is straightforward. Based on the ${ }^{1} \mathrm{H} N M R$ investigation of the 7 and 12 complexation, an equilibrium constant of log $K=4.3 \pm 0.6$ could be calculated. The in situ ${ }^{1} \mathrm{H}$ NMR investigations have revealed that the complex formation of $\mathbf{1 3}$ with monomer 7 and perfluorinated copolymer $\mathbf{c p - 7 - 1 0}$ takes place via both the lysine $-\mathrm{NH}_{3}{ }^{+}$and the alanine $-\mathrm{NH}_{3}{ }^{+}$moieties. However, in the case of homopolymer poly-7, the lysine- $\mathrm{NH}_{3}{ }^{+}$group coordination was observed exclusively. According to theoretical calculations, molecular switching of the crown ether structure of both the $\mathbf{7}$ monomer and its cp-7-10 copolymer were observed from 90 degrees bent to planar structure upon $-\mathrm{NH}_{3}{ }^{+}$ion coordination.
\end{abstract}

\section{Introduction}

Supramolecular chemistry utilizes reversible non-covalent bonding for the assembly of molecular architectures. ${ }^{1}$ Crown ethers (CEs) are well-known host molecules in supramolecular chemistry. Due to their excellent selectivity, crown ether-based molecular recognition motifs are widely used to synthesize polymers with unique properties. ${ }^{2,3}$ They can be involved either in the main chain or attached covalently to a polymer backbone as a side-chain. ${ }^{4}$ The synthesis of such host polymers can be carried out not only by classical polymerization

\footnotetext{
${ }^{a}$ Institute of Materials and Environmental Chemistry, Research Centre for Natural Sciences, Hungarian Academy of Sciences, Magyar tudósok körútja 2, P.O. Box 286, H-1519 Budapest, Hungary.E-mail: tuba.robert@ttk.mta.hu

${ }^{b}$ Department of Applied Chemistry, University of Debrecen, Egyetem tér 1, H-4032 Debrecen, Hungary

${ }^{c}$ Department of Organic Chemistry and Technology, Budapest University of Technology and Economics, Szent Gellért tér 4, H-1111 Budapest, Hungary $\dagger$ Electronic supplementary information (ESI) available. See DOI: 10.1039/ c9py00929a
}

methods but also via ring opening metathesis polymerization (ROMP) reactions. ${ }^{5,6}$ Crown ethers can form stable complexes not only with metal cations but also with protonated amines. ${ }^{7}$ This possibility has prompted many studies of CEs with peptides and proteins. ${ }^{8,9}$ The utilization of CEs in medical applications is emerging. ${ }^{10,11}$ For example, amino-crown ethers have been utilized for the delivery of 5-fluorouracil (5-FU), an anticancer agent used for the treatment of metastatic carcinomas of pancreas and breast. ${ }^{12}$ Moreover, several 18-crown-6 ethers have shown antitumor activity and reversal effect on multidrug resistance. ${ }^{13}$

We have recently reported the synthesis of vinyl alcohol (VA) copolymers having fine tunable polarities, which are considered as emerging nanocomposite materials for drug delivery applications. ${ }^{14 a}$

Fine tuning of the polarity of drug delivery polymers may enable preprogrammed and sustained drug release. ${ }^{14 b}$ Moreover, it is envisioned that the fine tuning of the polarity of the CEs containing host polymers should make possible the transport of highly hydrophilic biogenic amines in a non-polar environment using a well-adjusted lipophilic polymer/nano- 
composite matrix. For example, it is tentatively supposed that tagging of dopamine via non-covalent reversible bonds to semi- or non-polar host polymers may enable its direct transport through the blood-brain barrier, leading to alternative treatment of Parkinson's disease. ${ }^{15,16}$ Furthermore, the introduction of perfluorinated organic moieties may open the way to magnetic resonance imaging (MRI) active properties of the potential drug carrier macromolecules. ${ }^{17}$ Here, we report the synthesis and supramolecular assembly of hydroxyl and fluorine functionalized biogenic amine recognition host polymers.

\section{Results and discussion}

\section{Norbornene-functionalized pyridino-18-crown-6 ether (7) synthesis}

As shown in Scheme 1, norbornene-functionalized pyridino18-crown-6 ether 7 was synthesized via chelidonic acid (1) in $15 \%$ overall yield. 1 was prepared from diethyl oxalate and acetone in the presence of sodium ethoxide according to literature sources. ${ }^{18}$ Treatment of $\mathbf{1}$ with aqueous concentrated ammonium hydroxide resulted in chelidamic acid (2). ${ }^{19}$ Esterification was carried out with thionyl chloride and methanol leading to chelidamic acid dimethyl ester (3). ${ }^{20}$ Following the Mitsunobu reaction of 3 with the endo norbornene derivative 4 , the ether 5 could be obtained by column chromatography. The reduction of $\mathbf{5}$ to diol $\mathbf{6}$ followed by macrocyclization gave the crown ether 7 in moderate yield (42\%). When the mixture of endo/exo isomers of 5 was used without separation, the product 7 contained endo and exo stereoisomers in $74 \%$ and $26 \%$ ratios, respectively.

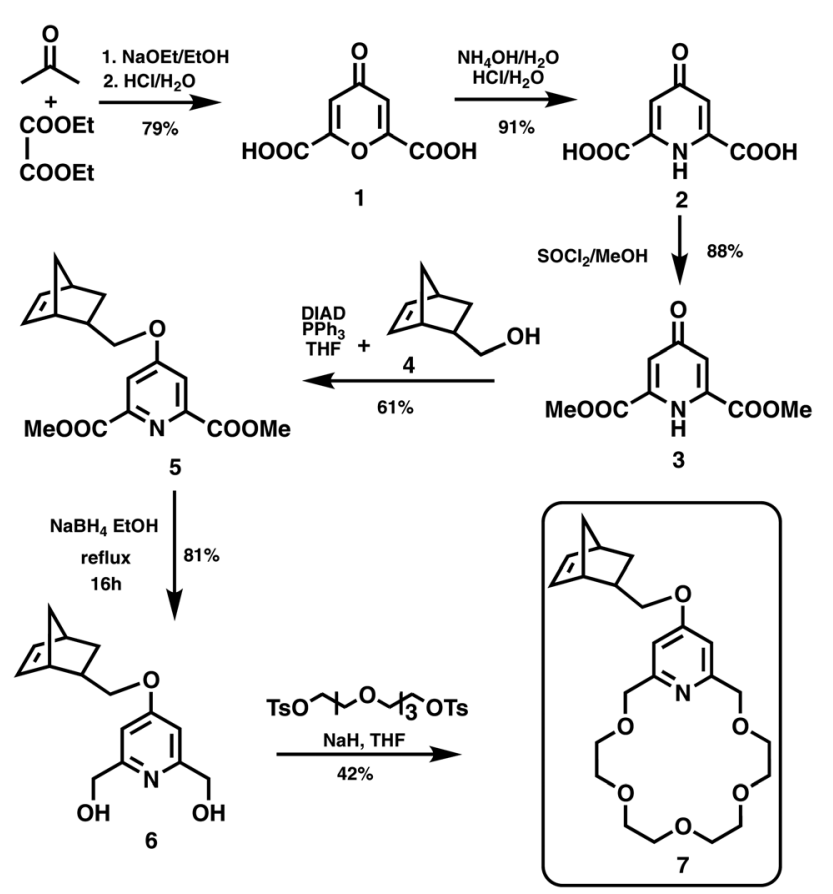

Scheme 1 Synthesis of norbornene-functionalized pyridino-18-crown6 ether (7).

\section{Complexation of pyridino-18-crown-6 ether (7) with biogenic} amines

The complexation of crown ether (7) with dopamine hydrochloride (12) (Fig. 1, 2 and Fig. S47†) and L-alanyl-L-lysine dipeptide hydrochloride (13) (Fig. 2 and Fig. S48†) has been investigated. Upon mixing 7 with 12 , the $\mathrm{C}(\mathrm{py})-\mathrm{CH}_{2}-\mathrm{O}$ proton signals of 7 shifted upfield significantly from 4.64 to $4.57 \mathrm{ppm}$ (Fig. 1). This is aligned with the literature data reported for the complexation of organic ammonium salts and similar pyridino-18-crown-6 ethers. ${ }^{21-24}$ The titration of 7 with 12 indicated a gradually increasing upfield shift of $\mathrm{C}(\mathrm{py})-\mathrm{CH}_{2}-\mathrm{O}$ signals of 7 (4.64 ppm) until reaching the stoichiometric ratio. However, as the stoichiometric ratio has been achieved there was no further significant shifts observed for the $\mathrm{C}(\mathrm{py})-\mathrm{CH}_{2}-\mathrm{O}$ signal in ${ }^{1} \mathrm{H}$ NMR spectra (Fig. 1). Based on the chemical shift changes, $\log K=4.3 \pm 0.6$ could be calculated, ${ }^{25}$ which is consistent with the reported data for similar complexes shown in Fig. S54.† Izatt et al. found a slightly lower $\log K$ value of 3.62 for the complexation of a bulkier isoalkyl-ammonium ion, $(R)$ 1-phenylethylamine with a less flexible dimethylated pyridino18-crown-6 ether molecule (see details of calculation in the ESI $\dagger$ ). ${ }^{25}$ The $K$ values for complexation of crown ethers using ammonium salts are in general high, and the equilibrium is shifted toward the complex formation side. ${ }^{21-24}$ Reproduction of the complexation using dipeptide $\mathbf{1 3}$ resulted in a similar supramolecular complex formation (see also ESI Fig. S48†).

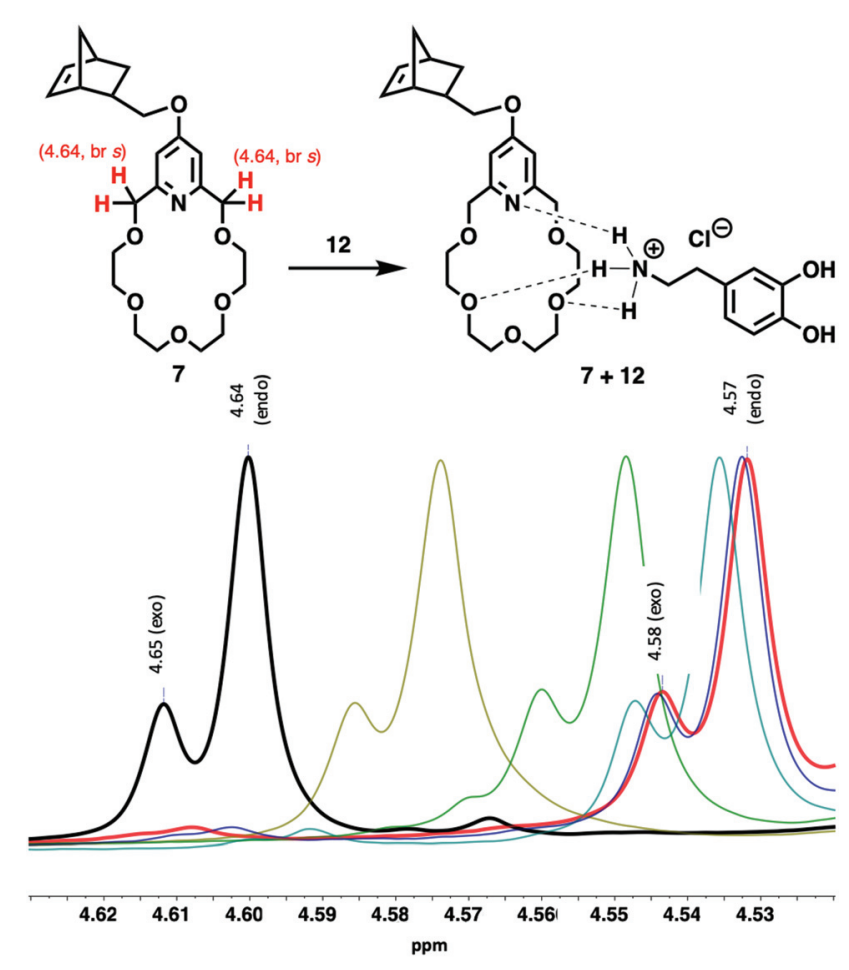

Fig. 1 Investigation of the complexation of 7 (endo/exo mixture) with 12 by a titration ${ }^{1} \mathrm{H}$ NMR method. Chemical shifts of pyridino-18-crown6 ether methylidine protons (red) vs. $12: 7$ molar ratios. Black: 0; brown: 0.3 ; green: 0.6; light blue: 1.0; dark blue: 1.5; red: $2.0\left(\mathrm{MeOD}-\mathrm{CD}_{2} \mathrm{Cl}_{2}\right.$ $1: 1$ mixture, [7] $=[12]=0.01 \mathrm{mmol} \mathrm{mL}^{-1}$ ). 
<smiles>Oc1ccc(CCNCC[Ge]Cl)cc1O</smiles>

Dopamine $\mathrm{HCl}$

12

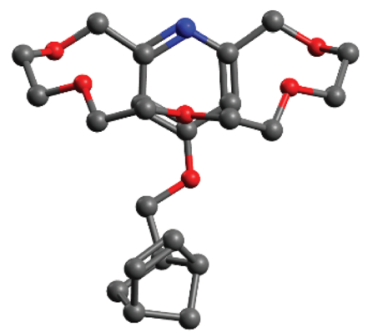

[front view]

Pyridino-18-crown-6 ether (7)
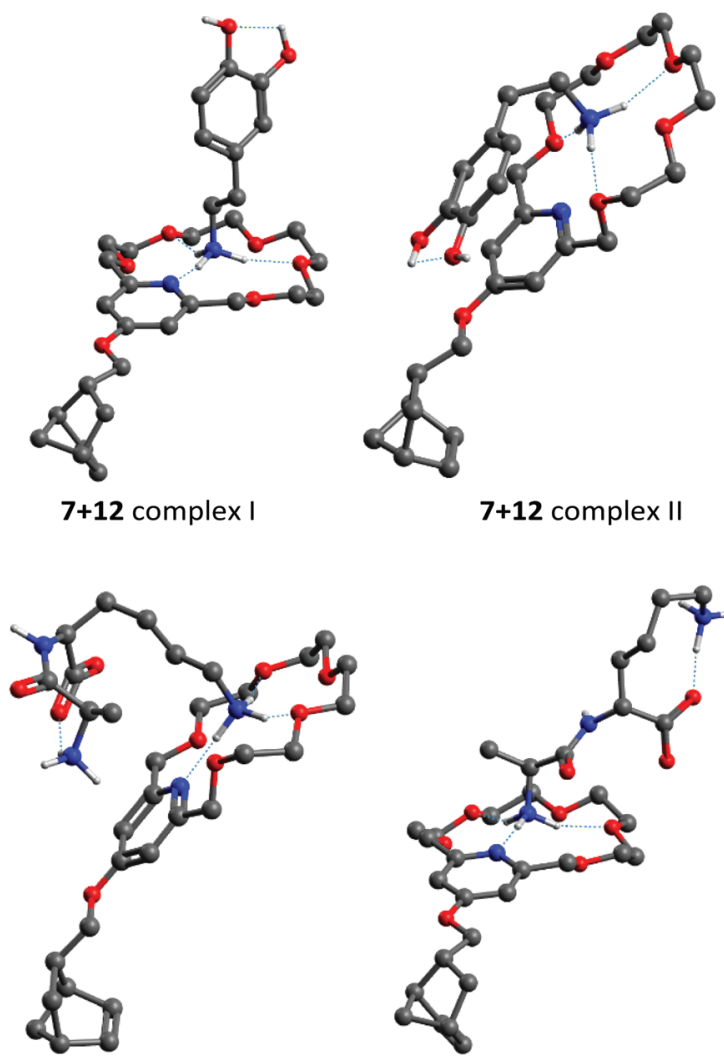

7+13 complex I

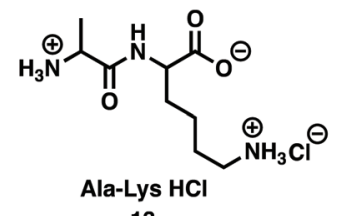

13
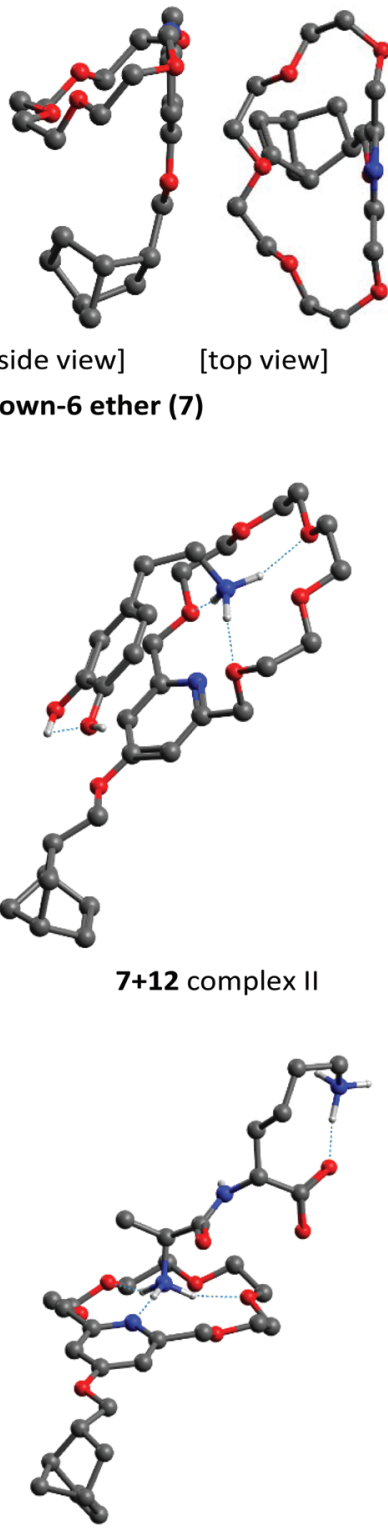

7+13 complex II [top view]

Fig. 2 Structural formulas of the dopamine $\mathrm{HCl}$ (12) and Ala-Lys $\mathrm{HCl}$ (13) (top two 2D structures). DFT optimized minimum energy conformer of pyridino-18-crown-6 ether (7) in methanol, shown in three perpendicular directions (top). 2-2 DFT optimized low energy conformers of complexes 7+12 (middle two) and 7+13 (bottom two) in an implicit methanol solvent (without the chloride ion). See text for the description of various complexes. In the ball and stick representation, carbon, nitrogen, oxygen and heteroatom-bound hydrogen atoms are drawn as grey, blue, red and white balls, respectively.
Electronic structure calculations using Gaussian 09 program package ${ }^{26}$ were carried out to determine the lowestenergy conformers of 7 and its complexes formed with dopamine-HCl (12) and L-alanyl-L-lysine dipeptide. $\mathrm{HCl}(\mathbf{1 3})$ at the M06-2X/cc-pVDZ level of density functional theory $(\mathrm{DFT})^{27,28}$ using the SMD implicit solvent model. ${ }^{29}$ Coordinates of optimized geometries are listed in the ESI. $\dagger$ Molecular dynamics (MD) studies with explicit solvent molecules and accurately parameterized solvent-solute interaction are needed to account for such a complex environment. ${ }^{30}$ Implicit solvent models do not allow the realistic treatment of solvent mixtures, especially in the case of different solvent types (e.g., protic $v s$. aprotic, highly polar $v s$. slightly polar/apolar).

The recent MD study of Benay and Wipff investigated solvation and complexation of alkali cations (picrate salts) by 18-crown-6 in a 90:10 chloroform/methanol mixture and found that the ions and the highly polar moieties are surrounded mainly by the polar and protic methanol molecules. ${ }^{30}$ Accordingly, they found that the calculated free energy change of complexation in the solvent mixture was very much like in pure methanol as intense interaction energies of polar and ionic groups dominated the energy change of the process. While specific MD studies are beyond the scope of the present work, these findings allow a realistic treatment of the complexation in methanol/dichloromethane and methanol/chloroform 50/50 solvent mixtures even with an implicit solvent model if pure methanol solvent is assumed.

Consequently, all electronic structure calculations presented here were carried out using methanol as an implicit solvent. A systematic (though probably non-exhaustive) DFT exploration of the high-dimensional conformational space of the crown ether ring identified several low-energy conformers for 7.

The one with the lowest energy is shown in three perpendicular directions in Fig. 2 (top three 3D structures). The minimum energy structure of the pyridino-18-crown-6 ether ring is largely different from the regular chair-type $S_{6}$-symmetric structure expected for 18-crown-6 ethers. Driven by secondary interactions, the crown shrinks and folds back over the pyridine ring. Complexation of 7 with dopamine and L-alanylL-lysine dipeptide hydrochloride (12 and 13) was investigated in methanol as an implicit solvent without explicit consideration of the chloride ion and by assuming a zwitterionic form for the dipeptide (Fig. 2).

During complexation, the crown ether folds out, and the cavity of the macrocycle expands and takes on a much more regular shape that can host the primary ammonium cations. Complexation of $\mathbf{1 2}$ proceeds by forming three H-bonds (distributed at every $\sim 120^{\circ}$ ) with the crown ether by two different ways: either involving the nitrogen atom of the pyridine ring $(7+12$ complex I) or without it $(7+12$ complex II) (Fig. 2 middle two 3D structures). The former is energetically favored when no other interactions of the ligand with the crown ether are considered. However, when the nitrogen atom is not involved in the complexation, the conformational motion of the dopamine allows the aromatic ring of the dopamine to fold back over the pyridine ring (Fig. 2 middle right) and this structure 
is stabilized by $\pi-\pi$ interactions. ${ }^{25}$ The protonated dipeptide cation can form a complex with the crown ether via either its lysine side chain $(\mathbf{7 + 1 3}$ complex I) or its $\mathrm{N}$-terminal $(\mathbf{7 + 1 3}$ complex II) (Fig. 2 bottom two 3D structures). The formation of the intramolecular $\mathrm{H}$-bond on the one hand significantly lowers the energy of the latter structure, and on the other hand, it hinders its conformational motion. The crown ether (7) and all complexes of $7+\mathbf{1 2}$ and $7+\mathbf{1 3}$ turned out to be very flexible as they have several low-energy very low-frequency vibrational modes $\left(\sim 20 \mathrm{~cm}^{-1}\right)$. Thus, to assess their relative stability through their standard free energy differences, full conformational sampling using MD simulations ${ }^{30}$ would be required. This, however, is beyond the scope of this study. Nevertheless, one can conclude that in proteins, which are the main targets of the proposed application, complexation through the lysine side chain will be dominant statistically as the number of lysine residues in them is usually much higher than one.

\section{Polymer synthesis}

Cycloolefin-functionalized crown ethers are expected to participate in polymerization and co-polymerization reactions such as ruthenium-catalyzed ring-opening metathesis polymerization (ROMP). ${ }^{31,32}$ Indeed, it was found that the norbornenefunctionalized pyridino-18-crown- 6 ether can readily be polymerized using commercially available ruthenium metathesis catalysts G2 (Grubbs $2^{\text {nd }}$ generation catalyst) and G3 (Grubbs $3^{\text {rd }}$ generation catalyst). Although G2 provides polynorbornene having a moderate polydispersity $(\fallingdotseq>1.5)$ - especially at relatively high catalyst loading - it has a higher functional group tolerance compared to the $\mathbf{G 3}$ metathesis catalysts. ${ }^{33}$ The ROMP reactions of norbornenes, in general, are relatively straightforward reactions, and they can be carried out at a low catalyst loading in any common organic solvent giving insoluble high molecular weight polymers. ${ }^{34}$

In these tests, however, a relatively high ( $2 \mathrm{~mol} \%)$ catalyst loading was applied to obtain relatively short polymers $\left(M_{\mathrm{W}}\right.$ (mass-average molar mass) $<20 \mathrm{kDa}$ ) with reasonable THF solubility for GPC analysis. The ROMP of 7 was carried out at room temperature in dichloromethane using the G2 catalyst giving the homopolymer poly-7 in 99\% isolated yield (Table 1). The formed polymer was sparingly soluble in $\mathrm{CDCl}_{3}, \mathrm{CD}_{2} \mathrm{Cl}_{2}$ and $\mathrm{CD}_{2} \mathrm{Cl}_{2} / \mathrm{MeOD}$ mixture $(1: 1)$; however, it was poorly soluble in THF, which did not allow its GPC analysis. When the polymerization was carried out using the $\mathbf{G} 3$ catalyst, the product showed increased THF solubility $\left(M_{\mathrm{w}}: 1.53 \times 10^{3} \mathrm{Da}, \nexists\right.$ (dispersity): 1.17). This observation can be explained by the significantly faster initiation and living polymerization character of the $\mathbf{G} 3$ catalyst leading to polymers with lower $M_{\mathrm{w}}$ values and narrow dispersity $(\nexists) .{ }^{33}$ MALDI-TOF MS measurements showed molecular weights corresponding to the oligomers containing 7 units $(\mathrm{m} / \mathrm{z}: 419$, Fig. S15 $\dagger)$. Preliminary co-polymerizations of 7 have been carried out with norbornene (8) at $1: 1$ and $1: 5$ molar ratios using the G3 catalyst. ${ }^{33}$ The $M_{\mathrm{w}}$ of the copolymers were $4.49 \times 10^{3} \mathrm{Da}(D: 1.68)$ at $7: 8=1: 1$ and $7.19 \times 10^{3} \mathrm{Da},(\nexists: 1.87)$ at $7: 8=1: 5$ molar ratio, respectively. Co-polymerization carried out at the $7: 8=1: 1$ molar ratio with the G2 catalyst resulted in a non-THF soluble polymer (98\% yield) (Scheme 2). However, the co-polymerization of 7 and 8 at the 1:5 molar monomer ratio led to a THF soluble polymer in $97 \%$ yield with a comparable molecular weight $\left(M_{\mathrm{w}}: 5.97 \times 10^{3} \mathrm{Da}\right)$ and higher polydispersity $(\nexists: 1.80)$. The MALDI-TOF MS measurements indicate that the oligomers are comprised of both $7(\mathrm{~m} / \mathrm{z}: 419)$ and $8(\mathrm{~m} / \mathrm{z}: 94)$ monomer units (Fig. S23 $\dagger$ ), as expected. Considering the observed molecular weights for $\mathbf{c p - 7 - 8}$ polymers (Table 1 ), it can be concluded that these data are consistent with the $M_{\mathrm{w}}$ value of polynorbornene synthesized under the similar condition and a slightly lower catalyst loading $(0.6 \mathrm{~mol} \%){ }^{35}$

Following the preliminary co-polymerization tests with $\mathbf{8}$, the incorporation of hydroxyl and perfluoro-tert-butyl groups into the host polymer chain was investigated. Perfluorinated moieties containing monomer $\mathbf{1 0}$ was synthesized by the reaction of the tosyl ester derivative of 4 (Tos-4) ${ }^{36}$ with the sodium salt of nonafluoro-tert-butyl alcohol ${ }^{37}$ in reasonable yield (60\%). Meanwhile, the bis-perfluorinated moieties containing monomer $\mathbf{1 1}$ has been synthesized by the Mitsunobu reaction ${ }^{38}$ via the reaction of $\mathbf{9}$ and nonafluoro-tert-butyl alcohol in moderate yield $(27 \%)$. The co-polymerization of crown ether 7 with 4 and 9 and perfluoro-tert-butyl-functionalized norbornenes 10 and $\mathbf{1 1}$ gave copolymers having randomly distributed dyads.

The co-polymerization of 7 with 4 in the stoichiometric ratio resulted in the $\mathbf{c p - 7 - 4}$ copolymer in quantitative yield. The polymer does not render any THF solubility. However, it is

Table 1 MW, polydispersity $(\Theta)$ and glass transition $\left(T_{\mathrm{g}}\right)$ and decomposition $\left(T_{\mathrm{d}}\right)$ temperature of the synthetized host polymers

\begin{tabular}{|c|c|c|c|c|c|c|c|c|c|}
\hline Entry & Polymer & Yield (\%) & $\mathrm{Cp}-\mathrm{M}-\mathrm{M}^{\prime} \mathrm{M} / \mathrm{M}^{\prime}$ & Catalysts & THF solubility & $M_{\mathrm{w}}(\mathrm{Da}) \times 10^{3}$ & $Ð$ & $T_{\mathrm{g}}\left({ }^{\circ} \mathrm{C}\right)$ & $T_{\mathrm{d}}\left({ }^{\circ} \mathrm{C}\right)$ \\
\hline 1 & poly-7 & 99 & NA & G2 & Poor & - & - & -36 & 347 \\
\hline 2 & poly-7 & 93 & NA & G3 & Sparing & 1.53 & 1.17 & - & - \\
\hline 3 & cp-7-8 & 98 & $1 / 1$ & G2 & Poor & - & - & 14.9 & 329 \\
\hline 4 & cp-7-8 & 95 & $1 / 1$ & G3 & Moderate & 4.49 & 1.68 & - & - \\
\hline 5 & cp-7-8 & 91 & $1 / 5$ & G3 & Moderate & 7.19 & 1.87 & - & - \\
\hline 6 & cp-7-8 & 97 & $1 / 5$ & G2 & Moderate & 5.97 & 1.80 & 19.7 & 248 \\
\hline 7 & cp-7-10 & 92 & $1 / 1$ & G2 & Poor & - & - & -16 & 295 \\
\hline 8 & cp-7-10 & 98 & $1 / 5$ & G2 & Sparing & 9.85 & 1.43 & $a$ & 307 \\
\hline 9 & cp-7-11 & 98 & $1 / 5$ & G2 & Moderate & 5.59 & 2.16 & $a$ & 403 \\
\hline
\end{tabular}

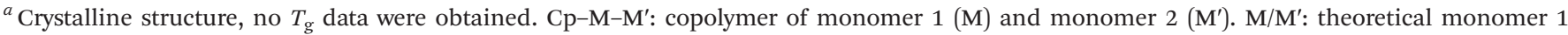
and monomer 2 ratio in the copolymer. 


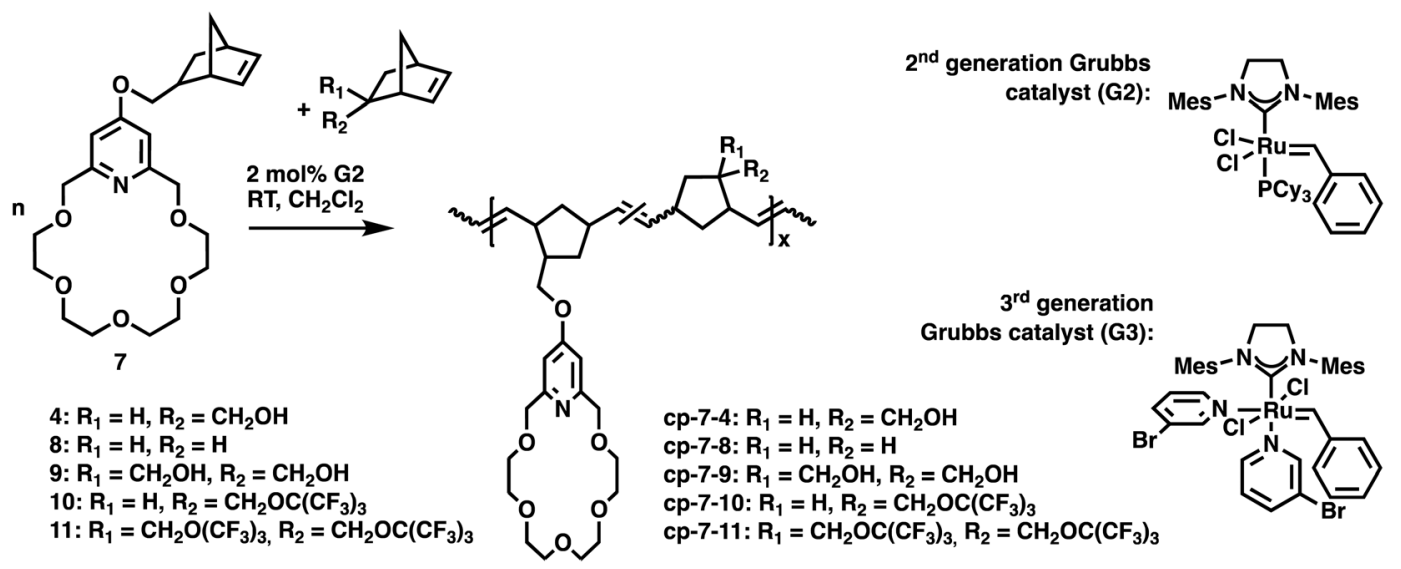

Scheme 2 Co-polymerization of crown ether-functionalized norbornenes.

sparingly soluble in the methylene chloride-methanol mixture. The co-polymerization of 7 with 9 led to the formation of entirely insoluble copolymer cp-7-9. These observations are consistent with literature data reporting that poly-4 and poly-9 have minimal solubility in common organic solvents. ${ }^{39}$ However, the introduction of perfluoro-tert-butyl units has significantly improved the copolymer solubility even in tetrahydrofuran. The co-polymerization of 7 has been carried out with $\mathbf{1 0}$ at $1: 1$ and $1: 5$ molar ratios using the G2 catalyst (cp-7-10 (1:1): 92\% and cp-7-10 (1:5): 98\% yield) in dichloromethane solution. cp-7-10 $(1: 1)$ was only sparingly soluble in THF; however, cp-7-10 (1:5) rendered reasonable THF solubility. The GPC tests of $\mathbf{c p - 7 - 1 0}(1: 5)$ revealed a reasonable $M_{\mathrm{w}}=$ $9.85 \times 10^{3} \mathrm{Da}(D: 1.43)$ value (Table 1$)$. As it was expected, the MALDI-TOF MS investigations have clearly indicated that the copolymers are comprised of both $7(\mathrm{~m} / \mathrm{z}: 419)$ and $10(\mathrm{~m} / \mathrm{z}$ : 342) monomer units as well (Fig. 3). Polymer cp-7-11 containing the bis-perfluoro-tert-butyl moieties in 1:5= 7:11 ratio has been synthesized in high yield (98\%). The polymer rendered a similar molecular weight and dispersity $\left(5.59 \times 10^{3} \mathrm{Da}\right.$, $Ð$ : 2.16) to copolymers $\mathbf{c p - 7 - 8}$ and $\mathbf{c p - 7 - 1 0}$ synthesized under similar reaction conditions (Table 1). Based on the DSC measurements (Table 1), it can be concluded that the inclusion of side groups increases the $T_{\mathrm{d}}$ values (as seen at poly-7: $347{ }^{\circ} \mathrm{C}$ and cp-7-11 (1:5): $403{ }^{\circ} \mathrm{C}$ vs. cp-7-8 (1:1): $329^{\circ} \mathrm{C}$; cp-7-8 (1:5): $\left.248^{\circ} \mathrm{C}\right)$. The co-polymerization of 7 with 8 at the $1: 1$ monomer ratio significantly increased the $T_{\mathrm{g}}$ value (poly-7 $=-36{ }^{\circ} \mathrm{C}$; poly-7-8 $\left.(1: 1)=14.9{ }^{\circ} \mathrm{C}\right)$. However, increasing the $7: 8$ monomer ratio up to $1: 5$ resulted in only a slight increase of the $T_{\mathrm{g}}$ value (poly-7-8 $\left.(1: 5)=19.7^{\circ} \mathrm{C}\right)$.

\section{Complexation of pyridino-18-crown-6 ether (7)-functionalized} polymers with biogenic amines

The complexation of poly-7 with 12 (Fig. 4 and Fig. S49†) and 13 (Fig. S50 $\dagger$ ) have been investigated by ${ }^{1} \mathrm{H}$ NMR spectroscopy in the MeOD- $\mathrm{CD}_{2} \mathrm{Cl}_{2}$ 1:1 solvent mixture at $30{ }^{\circ} \mathrm{C}$. As expected, upon complexation the poly-7 broad aromatic proton signals shifted upfield from 6.83 to $6.79 \mathrm{ppm}$; meanwhile, the aromatic protons of $\mathbf{1 2}$ have also shown significant shifts from
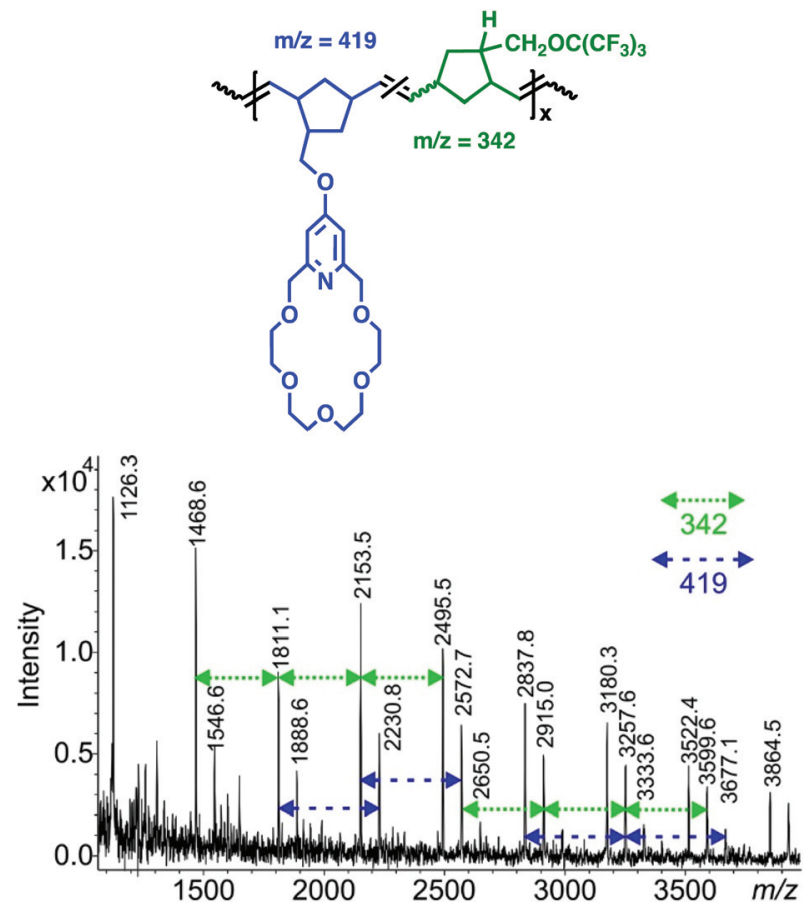

Fig. 3 MALDI TOF MS spectrum of copolymer cp-7-10, 7 (m/z: 419), 10 $(m / z: 342)(7 / 10=1 / 5)$ (linear mode, DHB/NaTFA).

6.80 (d), 6.76 (d) and 6.62 (dd) ppm to 6.76, 6.71 and 6.55 ppm, respectively (Fig. 4).

These observations are in accordance with the literature data reported for the supramolecular complex formation of pyridino-18-crown-6 ethers with protonated primary amines. ${ }^{21}$ Similar chemical shift could be clearly observed in the aliphatic proton region as well. The aliphatic $\mathrm{CH}_{2}$ proton signals of 12 shifted from $3.13(\mathrm{t})$ and $2.86(\mathrm{t}) \mathrm{ppm}$ to 3.09 and $2.80 \mathrm{ppm}$, respectively (Fig. 4). As was expected, the proton signals of $\mathbf{1 2}$ significantly broadened upon complexation with the crown ether-functionalized polymer.

The complexation of poly-7 with $\mathbf{1 3}$ also revealed significant changes of the chemical shifts of the reacting molecules. The 

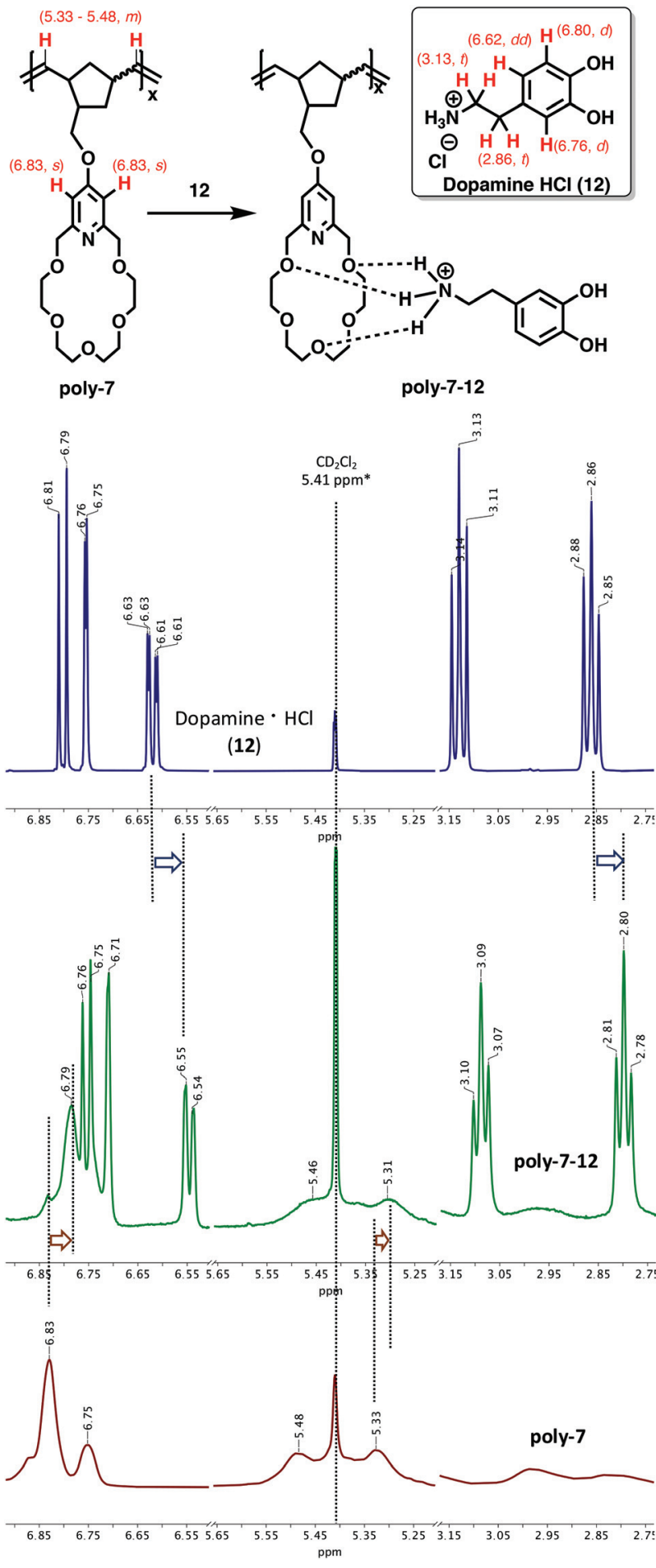

Fig. 4 Complexation of poly-7 (bottom) with Dopamine $\mathrm{HCl}, 12$ (top), and poly-7-12 complex (middle) (MeOD- $\mathrm{CD}_{2} \mathrm{Cl}_{2} 1: 1$ mixture, $30{ }^{\circ} \mathrm{C}$, [poly-7] $=$ [12] $=0.01 \mathrm{mmol} \mathrm{mL}^{-1}$ ).

aromatic proton signals of poly-7 shifted upfield from $6.83 \mathrm{ppm}$ to $6.79 \mathrm{ppm}$ (Fig. S50†). Unlike the complexation of 7 with 12, it can be seen that upon complexation of poly-7 with 13 the most characteristic peaks $\mathrm{CH}(\mathrm{t})(4.33 \mathrm{ppm})$ and $\mathrm{CH}_{2}(\mathrm{t})$ (2.95 ppm) of $\mathbf{1 3}$ have revealed significant chemical shifts to

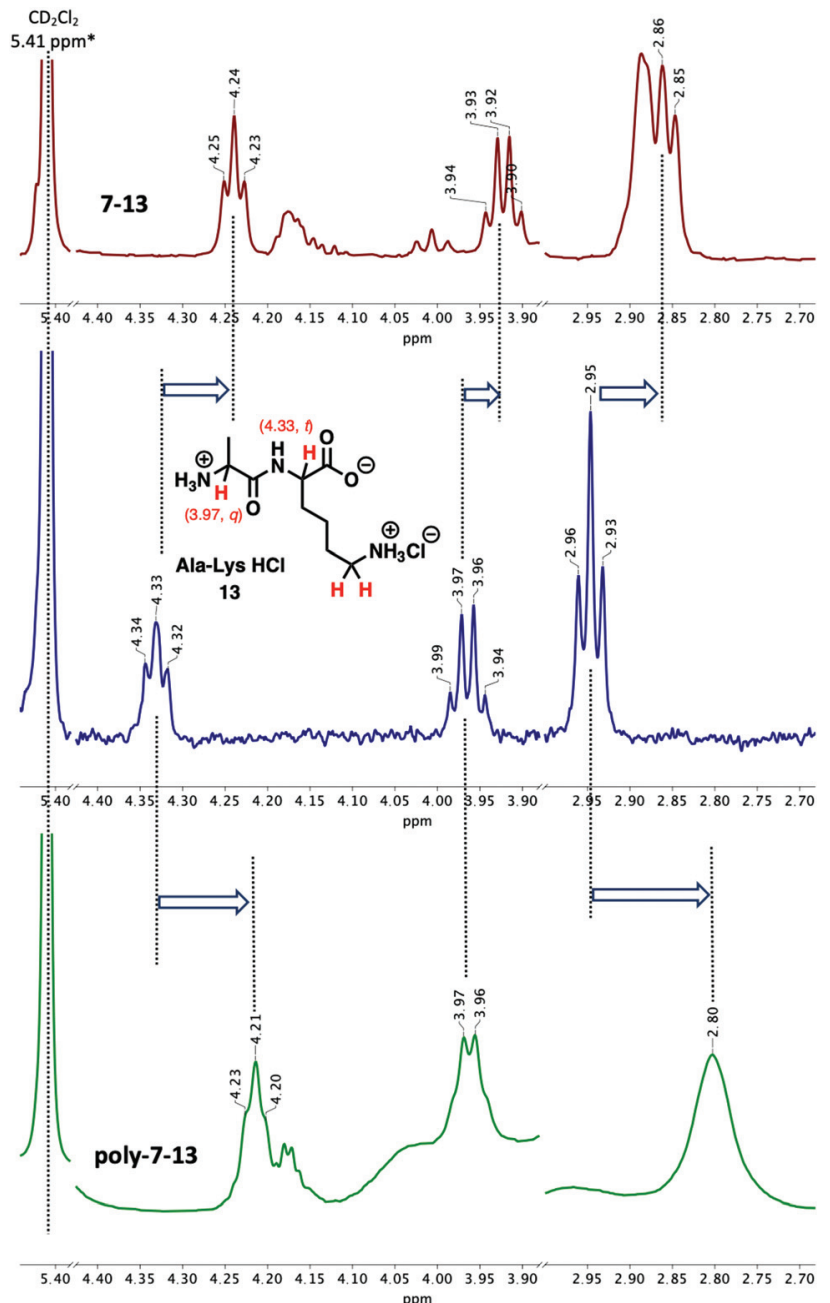

Fig. 5 Complexation of 13 (middle) with pyridino-18-crown-6 ether, 713 (top) and polymer, poly-7-13 (bottom) (MeOD- $\mathrm{CD}_{2} \mathrm{Cl}_{2} 1: 1$ mixture, $\left.30^{\circ} \mathrm{C},[7]=[13]=0.01 \mathrm{mmol} \mathrm{mL}^{-1}\right)$.

$4.21 \mathrm{ppm}$ and $2.80 \mathrm{ppm}$; meanwhile, the $\mathrm{CH}$ (q) peak at $3.97 \mathrm{ppm}$ did not show any significant changes (Fig. 5, bottom). This observation indicates that the complexation between poly-7 and $\mathbf{1 3}$ most probably occurs exclusively via the lysine $-\mathrm{NH}_{3}{ }^{+}$group rather than the alanine $-\mathrm{NH}_{3}{ }^{+}$moiety, unlike the complexation between $\mathbf{7}$ and $\mathbf{1 3}$ where all the three peaks revealed significant upshift indicating that it takes place by both $-\mathrm{NH}_{3}{ }^{+}$moieties (Fig. 5 , top).

Following the investigation of the complexation of homopolymer poly-7 with 12, the complexation of perfluoro tert-butyl groupfunctionalized copolymer cp-7-10 has been investigated (Fig. 6).

As expected, upon addition of $\mathbf{1 2}$ to a MeOD- $\mathrm{CD}_{2} \mathrm{Cl}_{2}$ solution of cp-7-10 (1:1), the aromatic proton signals of $\mathbf{1 2}(6.81$ (d), 6.75 (d) and 6.62 (dd) ppm) significantly shifted to 6.79 (d), 6.73 (d) and 6.60 (dd) ppm, respectively. Meanwhile, broadening of the proton peaks of $\mathbf{1 2}$ was observed.

The aliphatic proton signals of $\mathbf{1 2}$ have also shifted upfield from $3.13(\mathrm{t})$ and $2.86(\mathrm{t}) \mathrm{ppm}$ to $3.12(\mathrm{t})$ and $2.84(\mathrm{t}) \mathrm{ppm}$, respectively (Fig. 6 and Fig. S51†). Meanwhile, the broad aro- 

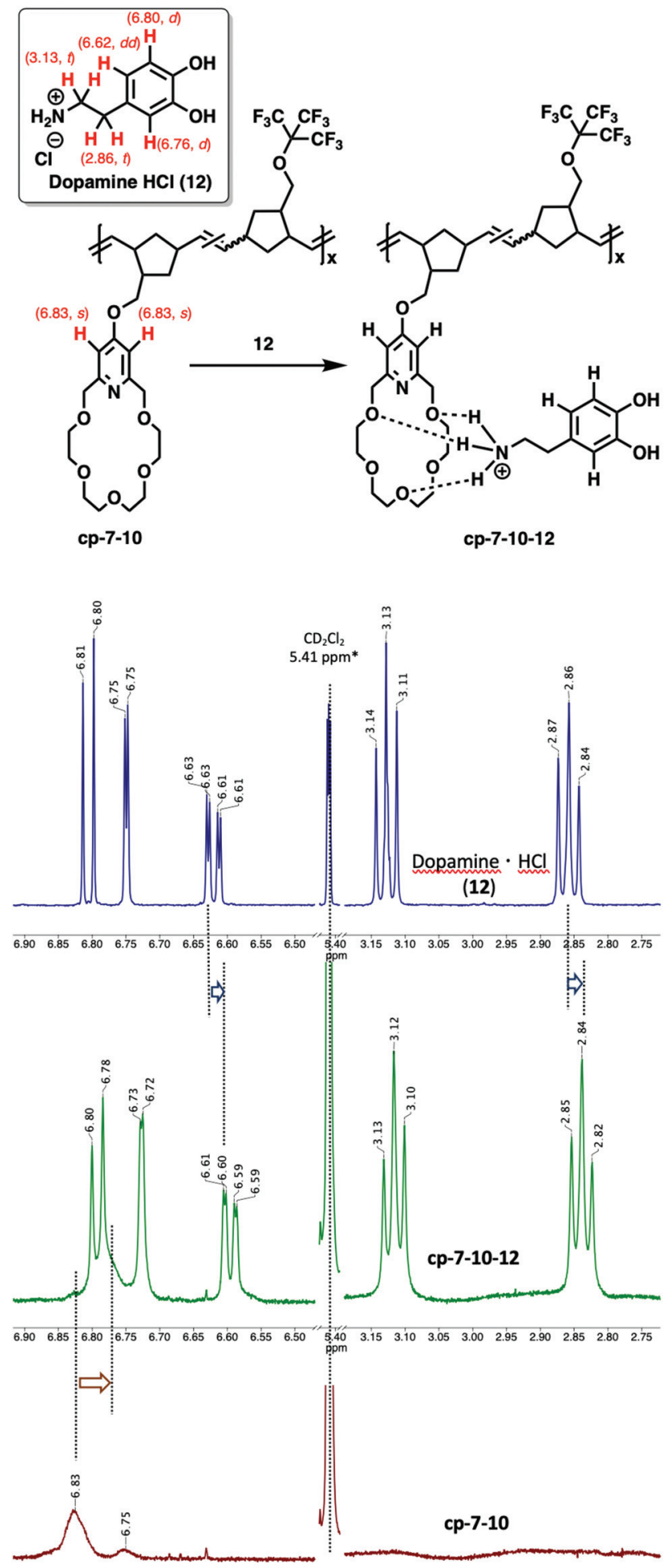

\begin{tabular}{lllllllllllllllllll}
6.90 & 6.85 & 6.80 & 6.75 & 6.70 & 6.65 & 6.60 & 6.55 & 6.50 & \multicolumn{1}{c}{5.40} & 3.15 & 3.10 & 3.05 & 3.00 & 2.95 & 2.90 & 2.85 & 2.80 & 2.75
\end{tabular}

Fig. 6 Complexation of poly-7-10 (1:1, bottom) with Dopamine $\cdot \mathrm{HCl}$, 12 (top), and poly-7-10-12 complex (middle) (MeOD- $\mathrm{CD}_{2} \mathrm{Cl}_{2}$ $1: 1$ mixture, $\left.30^{\circ} \mathrm{C},[\mathrm{cp}-7-10]=[12]=0.01 \mathrm{mmol} \mathrm{mL}^{-1}\right)$.

matic $\mathrm{CH}$ proton peaks of $\mathbf{c p - 7 - 1 0}$ were also shifted upfield from $6.83 \mathrm{ppm}$ to $6.77 \mathrm{ppm}$. The observed simultaneous upfield shifts and peak broadenings of $\mathbf{1 2}$ clearly indicate an interaction between the polymer (cp-7-10) and Dopamine- $\mathrm{HCl}$ (12). The complexation of cp-7-10 with Ala-Lys.HCl (13) led to similar shifts of the pyridino-18-crown-6 ether aromatic protons (from 6.83 (br) to $6.78(\mathrm{br}) \mathrm{ppm}$ ) and lysine protons (from $4.33(\mathrm{t})$ to $4.26(\mathrm{br}) \mathrm{ppm}$ and from $2.95(\mathrm{t})$ to $2.91(\mathrm{br})$ ppm) (Fig. S52 $\dagger$ ). Just as in the case of complexation of $\mathbf{c p - 7 - 1 0}$ with 12, the proton signal broadening of $\mathbf{1 3}$ were unambiguous, indicating the specific intermolecular interaction between cp-7-10 and Ala-Lys· $\mathrm{HCl}$ (13). It should be noted that based on the ${ }^{1} \mathrm{H}$ NMR spectra, there was significant upshift for the quartet signal of the Ala unit from $3.97 \mathrm{ppm}$ to $3.91 \mathrm{ppm}\left(\mathrm{CH}^{-}\right.$ $\mathrm{CH}_{3}$ ), indicating that most probably the complexation occurs not only via the protonated lysine side chain but also on the protonated N-terminal alanine dyad (Fig. S52 $\dagger$ ).

The formed copolymers are not only non-periodic, but also highly flexible; thus, they do not exhibit a well-defined geometry. The all-trans $\mathrm{H}-(\text { poly-7-10 })_{4}-\mathrm{H}$ alternating cooligomer can be considered as the most abundant possible dyad ${ }^{40}$ of the formed host polymers. A local optimum structure of its complex formed with $\mathbf{1 2}$ was determined in an implicit methanol solvent using the PM6 semiempirical theory and is shown as an illustration in Fig. 7 to help the reader to visualize them. ${ }^{41}$

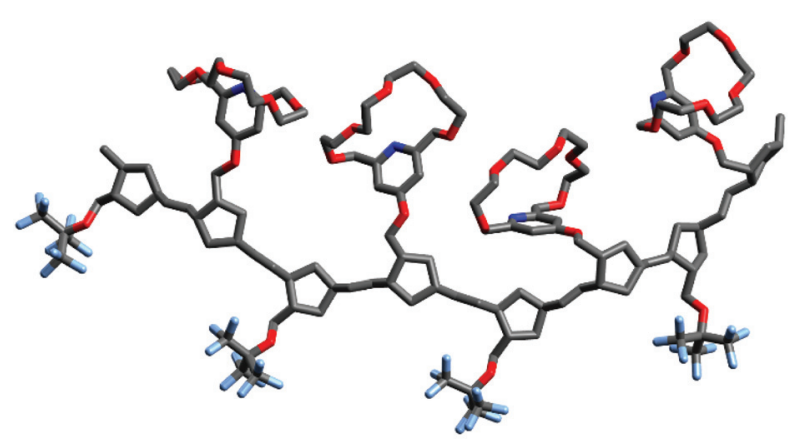

all-trans $\mathrm{H}-(\mathrm{cp}-7-10) 4-\mathrm{H}$

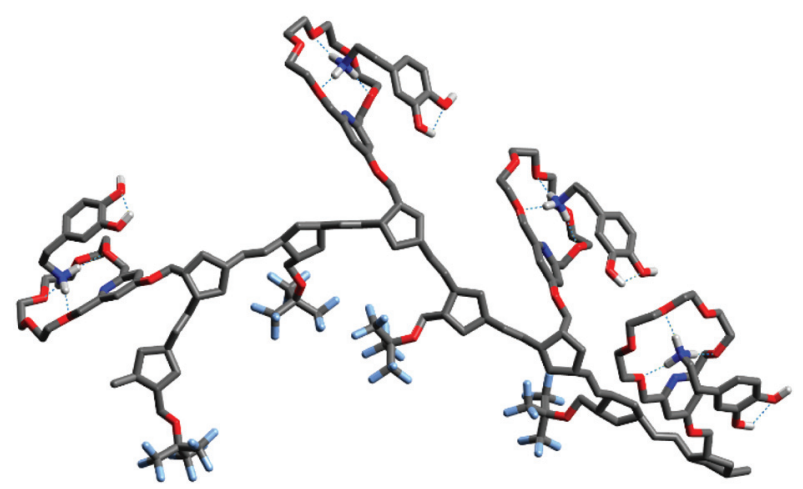

all-trans H-(cp-7-(10+12))4-H

Fig. 7 A local optimum structure of the all-trans $\mathrm{H}-(\mathrm{cp}-7-10)_{4}-\mathrm{H}$ cooligomer and its complex with $12(\mathrm{cp}-7-(10+12))$ determined at the PM6 level of theory in an implicit methanol solvent. Molecular switching to planar structure of pyridino-18-crown- 6 ether moieties upon complexation with 12 . In the ball and stick representation carbon, nitrogen, oxygen and heteroatom-bound hydrogen atoms are drawn as grey, blue, red and white balls, respectively. 
Coordinates of optimized geometries are listed in the ESI. $\uparrow$ If no complexation takes place, the strong attraction between the tilted and folded crown ether units aligns them and bends the copolymer chain toward the side groups. In the complex state, the side groups are positively charged due to the presence of the primary ammonium ions. The strong electrostatic repulsion is only partially ameliorated by the methanol solvent (and the scattered, solvated chloride ions). Thus, the side groups tilt away from each other and the polymer chain becomes distorted.

\section{Conclusions}

In summary, a wide range of copolymers having host (pyridino-18-crown-6 ether), $\mathrm{OH}$ and perfluoro tert-butyl functionalities have been synthetized via ruthenium-catalyzed ring opening metathesis polymerization.

The complexation of poly-7 and its perfluoro-tert-butyl group containing copolymers (poly-7-10) with biogenic amines including dopamine (12) and L-alanyl-L-lysine dipeptide (13) has led to the formation of the supramolecular complexes indicated by ${ }^{1} \mathrm{H}$ NMR spectroscopy. Upon complexation, significant upfield shift of the proton signals $(0.02-0.06 \mathrm{ppm})$ of both reactants and peak broadening of the biogenic amines were observed. The investigations have revealed that the complex formation of $\mathbf{1 3}$ with monomer $\mathbf{7}$ and copolymer cp-710 may take place via either the lysine or alanine $-\mathrm{NH}_{3}{ }^{+}$ moieties. However, in the case of poly-7, the lysine amine group coordination was observed exclusively.

The experimental data have been supported by theoretical calculations, also indicating that the complexation of a biogenic amine to the presented host polymer is straightforward.

It is envisioned that these polymers may have potential to serve as "biogenic amine carriers" opening new alternatives for drug delivery applications.

\section{Conflicts of interest}

There are no conflicts to declare.

\section{Acknowledgements}

This work was funded by grants provided by the National Competitiveness and Excellence Program, Hungary (NVKP-161-2016-0007), and by the BIONANO-GINOP-2.3.2-15-201600017 project. The authors are grateful to Materia, Inc., for providing G2. Tibor Nagy and Péter Huszthy are grateful to the Hungarian Academy of Sciences and National Research, Development and Innovation Office (NKFIH) for financial support under Grant No. PD 120776 and K128473, for János Bolyai Research Fellowship BO/00279/16/7 and for the Hungarian NIIF HPC infrastructure. Ervin Kovács is grateful to the National Research, Development and Innovation Office (NKFIH) for Postdoctoral Excellence Award (PD 128612). Attila
Domján is acknowledged for solid NMR analysis. The authors thank Prof. John A. Gladysz (TAMU) for the revision and the constructive comments.

\section{Notes and references}

1 L. Brunsveld, B. J. B. Folmer, E. W. Meijer and R. P. Sijbesma, Chem. Rev., 2012, 101, 4071-4097.

2 C. R. South, M. N. Higley, K. C. F. Leung, D. Lanari, A. Nelson, R. H. Grubbs, J. F. Stoddart and M. Weck, Chem. - Eur. J., 2006, 12, 3789-3797.

3 C. R. South, K. C. F. Leung, D. Lanari, J. F. Stoddart and M. Weck, Macromolecules, 2006, 39, 3738-3744.

4 U. Tunca and Y. Yagci, Prog. Polym. Sci., 1994, 19, 233-286.

5 R. Ji, C. G. Chao, Y. C. Huang, Y. K. Lan, C. L. Lu and T. Y. Luh, Macromolecules, 2010, 43, 8813-8820.

6 E. Eder, P. Preishuber-Pflügl and F. Stelzer, J. Mol. Catal. A: Chem., 2000, 160, 63-69.

7 V. Rüdiger, H. J. Schneider, V. P. Solov'ev, V. P. Kazachenko and O. A. Raevsky, Eur. J. Org. Chem., 1999, 1847-1856.

8 S. W. Lee, H. N. Lee, H. S. Kim and J. L. Beauchamp, J. Am. Chem. Soc., 1998, 120, 5800-5805.

9 R. R. Julian and J. L. Beauchamp, J. Am. Soc. Mass Spectrom., 2002, 13, 493-498.

10 X. Liu, S. Zhu, S. Wu, P. Wang and G. Han, Colloids Surf., A, 2013, 417, 140-145.

11 I. A. Darwish and I. F. Uchegbu, Int. J. Pharm., 1997, 159, 207-213.

12 R. Muzzalupo, F. P. Nicoletta, S. Trombino, R. Cassano, F. Iemma and N. Picci, Colloids Surf., B, 2007, 58, 197-202.

13 I. Guberović, M. Marjanović, M. Mioč, K. Ester, I. Martinkleiner, T. Š. Ramljak, K. Mlinarić-majerski and M. Kralj, Sci. Rep., 2018, 8, 14467.

14 (a) T. Feczkó, G. Merza, G. Babos, B. Varga, E. Gyetvai, L. Trif, E. Kovács and R. Tuba, Int. J. Pharm., 2019, 562, 333-341; (b) S. Miyazaki, S. Takeuchi, W. Hou, N. Hashiguchi, C. Yokouchi, M. Takada, M. Hosokawa, Y. Koga and H. Kobayashi, Chem. Pharm. Bull., 1985, 33, 2490-2498.

15 C. Saraiva, C. Praça, R. Ferreira, T. Santos, L. Ferreira and L. Bernardino, J. Controlled Release, 2016, 235, 34-47.

16 A. M. Grabrucker, B. Ruozi, D. Belletti, F. Pederzoli, F. Forni, M. A. Vandelli and G. Tosi, Tissue Barriers, 2016, 4, e1153568.

17 S. Decato, T. Bemis, E. Madsen and S. Mecozzi, Polym. Chem., 2014, 5, 6461-6471.

18 E. R. Riegel and F. Zwilgmeyer, Org. Synth., 1937, 2, 126-128.

19 E. R. Riegel and M. C. Reinhard, J. Am. Chem. Soc., 1926, 48, 1334-1345.

20 J. S. Bradshaw, P. Huszthy, T. Wang, C. Zhu, A. Y. Nazarenko and R. M. Izatt, Supramol. Chem., 1993, 1, 267-275.

21 T.-M. Wang, J. S. Bradshaw, J. C. Curtis, P. Huszthy and R. M. Izatt, J. Inclusion Phenom. Mol. Recognit. Chem., 1993, 16, 113-122. 
22 T.-M. Wang, J. S. Bradshaw and R. M. Izatt, J. Heterocycl. Chem., 1994, 31, 1097-1114.

23 C.-Y. Zhu, J. S. Bradshaw, J. L. Oscarson and R. M. Izatt, J. Inclusion Phenom. Mol. Recognit. Chem., 1992, 12, 275-289.

24 (a) J. S. Bradshaw, P. Huszthy, C. W. McDaniel, C.-Y. Zhu, N. K. Dalley, R. M. Izatt and S. Lifson, J. Org. Chem., 1990, 55, 3129-3137; (b) S. V. Brignell and D. K. Smith, New J. Chem., 2007, 31, 1243-1249.

25 R. M. Izatt, T. Wang, J. K. Hathaway, X. X. Zhang, J. C. Curtis, J. S. Bradshaw, C. Y. Zhu and P. Huszthy, J. Inclusion Phenom. Mol. Recognit. Chem., 1994, 17, 157-175.

26 M. J. Frisch, G. W. Trucks, H. B. Schlegel, G. E. Scuseria, M. A. Robb, J. R. Cheeseman, G. Scalmani, V. Barone, B. Mennucci, G. A. Petersson, H. Nakatsuji, M. Caricato, X. Li, H. P. Hratchian, A. F. Izmaylov, J. Bloino, G. Zheng, J. L. Sonnenberg, M. Hada, M. Ehara, K. Toyota, R. Fukuda, J. Hasegawa, M. Ishida, T. Nakajima, Y. Honda, O. Kitao, H. Nakai, T. Vreven, J. A. Montgomery Jr., J. E. Peralta, F. Ogliaro, M. Bearpark, J. J. Heyd, E. Brothers, K. N. Kudin, V. N. Staroverov, R. Kobayashi, J. Normand, K. Raghavachari, A. Rendell, J. C. Burant, S. S. Iyengar, J. Tomasi, M. Cossi, N. Rega, J. M. Millam, M. Klene, J. E. Knox, J. B. Cross, V. Bakken, C. Adamo, J. Jaramillo, R. Gomperts, R. E. Stratmann, O. Yazyev, A. J. Austin, R. Cammi, C. Pomelli, J. W. Ochterski, R. L. Martin, K. Morokuma, V. G. Zakrzewski, G. A. Voth, P. Salvador, J. J. Dannenberg, S. Dapprich, A. D. Daniels, Ö. Farkas, J. B. Foresman, J. V. Ortiz, J. Cioslowski and D. J. Fox, Gaussian Inc., Wallingford, CT, 2009.
27 Y. Zhao and D. G. Truhlar, Theor. Chem. Acc., 2008, 120, 215-241.

28 T. H. Dunning, J. Chem. Phys., 1989, 90, 1007-1023.

29 A. V. Marenich, C. J. Cramer and D. G. Truhlar, J. Phys. Chem. B, 2009, 113, 6378-6396.

30 G. Benay and G. Wipff, New J. Chem., 2016, 40, 46624671.

31 C. W. Bielawski and R. H. Grubbs, in Controlled and Living Polymerizations, 2009, pp. 297-342.

32 C. W. Bielawski and R. H. Grubbs, Prog. Polym. Sci., 2007, 32, 1-29.

33 T. Choi and R. H. Grubbs, Angew. Chem., Int. Ed., 2003, 42, 1743-1746.

34 J. Suriboot, Y. Hu, T. J. Malinski, H. S. Bazzi and D. E. Bergbreiter, ACS Omega, 2016, 1, 714-721.

35 R. Tuba, R. Corrêa Da Costa, H. S. Bazzi and J. A. Gladysz, ACS Catal., 2012, 2, 155-162.

36 V. De Matteis, F. L. Van Delft, J. Tiebes and F. P. Rutjes, Eur. J. Org. Chem., 2006, 1166-1176.

37 D. Szabó, J. Mohl, A. M. Bálint, A. Bodor and J. Rábai, J. Fluor. Chem., 2006, 127, 1496-1504.

38 K. C. Kumara Swamy, N. N. Bhuvan Kumar, E. Balaraman and K. V. P. Pavan Kumar, Chem. Rev., 2009, 109, 2551-2651.

39 U. Frenzel, T. Weskamp, F. J. Kohl, W. C. Schattenmann, O. Nuyken and W. A. Herrmann, J. Organomet. Chem., 1999, 586, 263-265.

40 R. Tuba, M. Al-Hashimi, H. Bazzi and R. Grubbs, Macromolecules, 2014, 47, 8190-8195.

41 J. J. P. Stewart, J. Mol. Model., 2007, 13, 1173-1213. 